\title{
Diabetes mellitus and the risk of cholangiocarcinoma: an updated meta-analysis
}

\author{
Junshan Li ${ }^{1,2}$, Tianjie $\mathrm{Han}^{3}$, Linlin $\mathrm{Xu}^{4}$, Xiaotian Luan ${ }^{4}$ \\ ${ }^{1}$ Department of Gastroenterology, Shandong Provincial Hospital, Shandong University, Shandong, China \\ 2Department of Gastroenterology, Tai'an Central Hospital, Tai'an, Shandong, China \\ ${ }^{3}$ Department of Hematology, Shandong Provincial Hospital, Shandong University, Jinan, China \\ ${ }^{4}$ Department of Pathology, Tai'an Central Hospital, Tai'an, Shandong, China
}

Prz Gastroenterol 2015; 10 (2): 108-117

DOI: $10.5114 / p g .2015 .49004$

Key words: cholangiocarcinoma, diabetes mellitus, meta-analysis.

Address for correspondence: Junshan Li, Department of Gastroenterology, Taian Central Hospital, Shandong Provincial Hospital, 271000 Taian, China, phone: +86 13854876889, e-mail: songzhenhefan@163.com

\begin{abstract}
Introduction: A number of studies have shown that diabetes mellitus is implicated in susceptibility to several cancers. However, the relationship between diabetes and cholangiocarcinoma remain unclear.

Aim: To quantitatively assess the relationship between diabetes and incidence of cholangiocarcinoma in cohort and case-control studies.

Material and methods: A literature search was performed for entries from 1996 to 2014 using the PubMed and EMBASE databases. Studies were included if they reported odds ratios (OR) and corresponding $95 \% \mathrm{Cl}$ of cholangiocarcinoma with respect to diabetes mellitus.

Results: Twenty studies met the inclusion criteria, which included fifteen case-control studies and five cohort studies from Asia $(n=11)$, the United States $(n=5)$, and Europe $(n=4)$. Compared with individuals without diabetes, the pooled OR of cholangiocarcinoma was 1.74 (95\% Cl: 1.62-1.87, $p=0.568$ for heterogeneity) for patients with diabetes, ICC (summary RR, 1.93; $95 \% \mathrm{Cl}: 1.65-2.25 ; p=0.037$ for heterogeneity), and ECC (summary RR, $1.66 ; 95 \% \mathrm{Cl}: 1.39-1.98 ; p=0.001$ for heterogeneity). The funnel plot revealed no evidence for publication bias concerning diabetes and the risk of CC (including ICC and ECC).

Conclusions: The findings from this meta-analysis suggest that diabetes may increase the risk of cholangiocarcinoma. This relationship needs to be confirmed by further follow-up studies.
\end{abstract}

\section{Introduction}

Cholangiocarcinoma (CC) is one of the most lethal human malignant tumours. Anatomically, CC can be classified as either intrahepatic cholangiocarcinoma (ICC) and extrahepatic cholangiocarcinoma (ECC), according to its location [1]. Incidence and mortality rates for CC have risen across the world [2]. In the UK, CC has killed approximately 1500 people annually since the mid-1990s, with approximately equal numbers of men and women [3]. Because of the difficulty in obtaining an early diagnosis, the prognosis is extremely poor [4], even with surgical and chemotherapy intervention.

There are several established risk factors for CC, such as primary sclerosing cholangitis (PSC), which is the commonest known predisposing factor for CC in the western world [5]. Other factors including chronic intraductal gallstones, liver fluke, choledochal (bile duct) cysts and Caroli's disease (intrahepatic biliary cysts), bile duct adenoma and biliary papillomatosis, Thorotrast, inflammatory bowel disease (IBD), and chronic typhoid carriage [6-9]. Many studies have been conducted to explore potential risk factors of CC. Chronic viral hepatitis B or C, obesity, diabetes, fatty liver disease, alcohol, smoking, polymorphisms of genes, inflammation, and biliary transporters may also be risk factors.

Several studies have found that diabetes can increase the risk of cancers, including cancers of the breast, pancreas, liver, and non-Hodgkin's lymphoma [10-12]. Also, some cohort and case-control studies have been conducted to estimate the relationship between diabetes and CC. But the results were controversial. Some studies found that diabetes can increase the risk 
of CC. Insulin and insulin-like growth factor-1 (IGF-1) are related to CC progress, but some other studies found no relation between them.

\section{Aim}

Therefore, a meta-analysis was performed to quantitatively assess the relationship between diabetes and the risk of CC in humans.

\section{Material and methods}

\section{Data sources and searches}

We screened the relevant studies from the search engines of PubMed and EMBASE (last search update performed on 07/2014), using two investigators independently, with the Medical Subject Heading (MeSH) terms 'diabetes mellitus', 'diabetes', 'cholangiocarcinoma', 'intrahepatic', 'extrahepatic', 'bile duct cancer', and 'epidemiologic studies', without language limit. Furthermore, we reviewed reference lists of retrieved articles to search for more studies.

\section{Inclusion and exclusion criteria}

Studies were included in the meta-analysis if they fulfilled the following criteria: (1) cohort or case-control design; (2) one of the exposure interests was diabetes mellitus (DM); (3) one of the outcomes of interests was ICC, ECC, or CC; (4) relative risk (RR) in cohort studies or odds ratio (OR) in case-control studies and their $95 \%$ confidence intervals ( $\mathrm{Cl}$ ) (or data to calculate them) were reported. If data were duplicated in more than one study, the estimated effects controlled for the most appropriate confounders were included.

\section{Data extraction}

According to the MOOSE (Meta-analysis Of Observational Studies in Epidemiology) guideline for reporting on meta-analyses of observational studies $[11,13]$, the data were extracted by two investigators independently. The information of each study was extracted as follows: the first author's last name; the region/country where the study was conducted; the year of publication; the number of cases; the mean age of cases and controls; diagnostic criteria; the manner in which the controls were selected; OR, RR, or hazard ratio (HR) of CC and corresponding 95\% Cl for diabetes; and covariates adjusted in the statistical analysis. Discrepancies were resolved by discussion with a third investigator and a consensus was reached.

\section{Statistical analysis}

The study-specific, most adjusted OR, RR, or HR was used to compute a summary OR and its $95 \% \mathrm{CI}$. Relative risks and $\mathrm{HR}$ were directly considered as OR. The statistical heterogeneity among the studies was estimated by the $\chi^{2}$ test-based $Q$-statistic, and a significant $Q$-statistic $(p<0.10)$ indicated heterogeneity across the studies [14]. The pooled OR was calculated by a fixed effect model (using the Mantel-Haenszel method) or a random effect model (using the DerSimonian-Laird method) according to the heterogeneity among studies $[15,16]$. The potential publication bias was evaluated using both Begg's funnel plot and Egger's test, and $p<0.05$ was considered statistically significant in publication bias [17]. Analyses were performed by using Stata version 12.0 (StataCorp LP, College Station, TX, USA). A $p$-value $<0.05$ was considered statistically significant, and all the $p$ values were two sided.

\section{Results \\ Characteristics of literature search and studies}

There were 20 studies included in this meta-analysis [18-37]. The continents or countries in which the studies were conducted were as follows: Asia $(n=11)$, the United States $(n=5)$, and Europe $(n=4)$. Characteristics of the studies are shown in Table $I$.

The 15 case-controlled studies reported a total of 3610 cases with ECC and 6380 cases with ICC. And the report from Grainge presented results for 372 cases with CC [25]. Among these 10,362 cases, 2399 cases with diabetes were reported (Table I), whereas, among 351,908 controls, 41,815 patients had diabetes. The control individuals included originated from a population-based [19-21, 23, 25, 26] or hospital-based setting [18, 22, 24, 27-32]. Diabetes status was ascertained by a self-reported history [19] of DM or hospital records [18, 20, 21, 24, 26-32], with the exception of three studies in which the methods of DM ascertainment were not available [22, 23, 25]. Ascertainment of ECC or ICC was based on histological methods or a review of medical records in 12 studies, and the remaining three studies were based on diagnostic codes [19-21]. Adjustments were made for potential confounders of tor more factors in studies 12 of 13, with the exception of 2 studies in which only the univariate OR was available [20, 22].

We identified five cohort studies that showed an association between DM and the risk of ICC or ECC (Table II). Among these five studies, the standardised incidence ratio as a measure of RR was used in two diabetic cohorts, and the other three studies used rate ratio as the measure of $\operatorname{RR}[33,37]$. These five cohort studies comprised between 56,881 and 836,283 persons with a median follow-up period of 6.7 years, reporting a total of 878 incident cases of ICC or ECC. The methods of DM ascertainment were based on medical records in three studies, and in the other two studies they were 


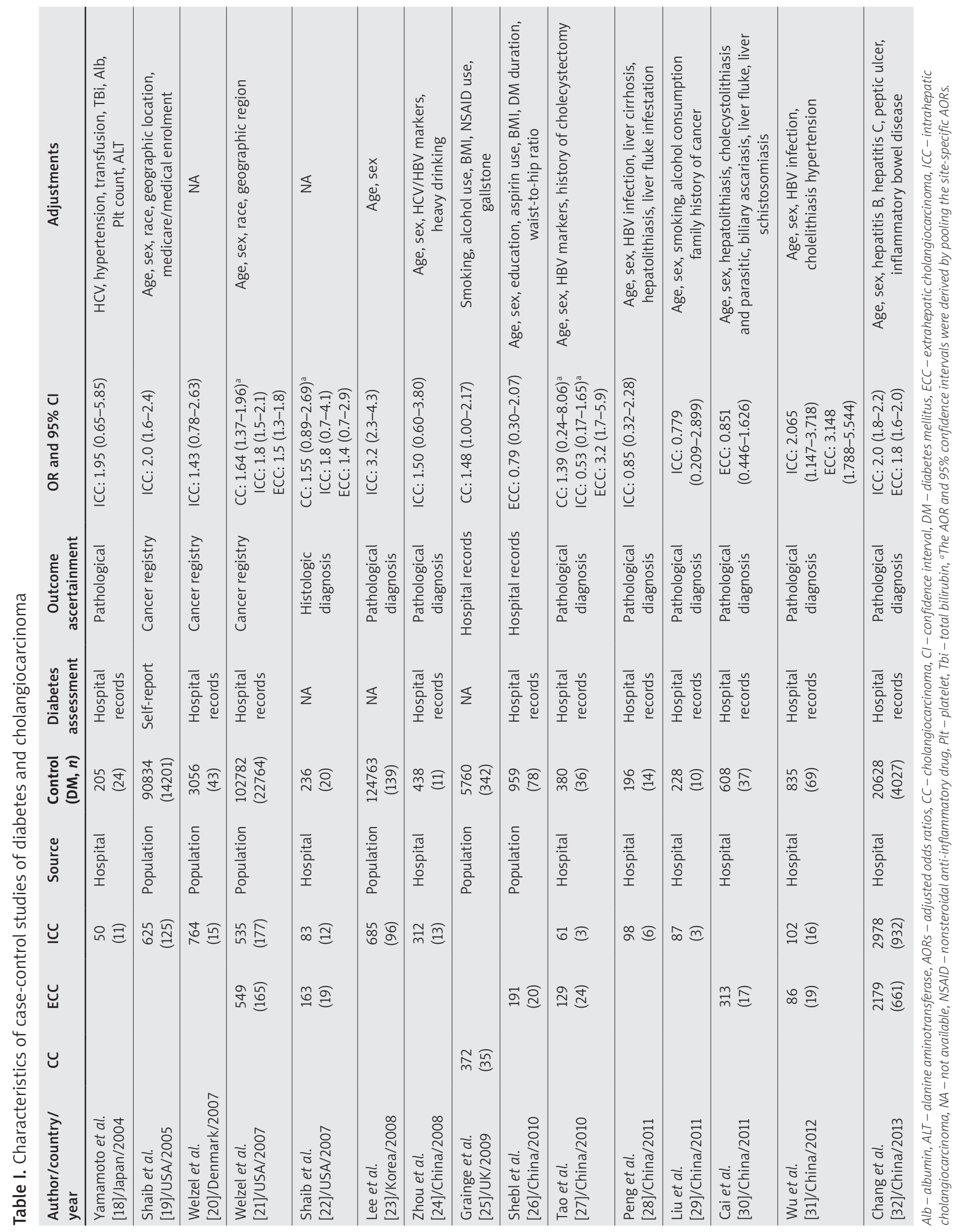


Table II. Characteristics of cohort studies of diabetes and cholangiocarcinoma

\begin{tabular}{|c|c|c|c|c|c|c|c|c|}
\hline $\begin{array}{l}\text { Author/ } \\
\text { country/year }\end{array}$ & $\begin{array}{l}\text { Number } \\
\text { of patients }\end{array}$ & $\begin{array}{l}\text { Demographics } \\
\text { of all patients } \\
\text { (age in years) }\end{array}$ & $\begin{array}{l}\text { Diabetes } \\
\text { assess- } \\
\text { ment }\end{array}$ & $\begin{array}{l}\text { Cancer } \\
\text { ascertain- } \\
\text { ment }\end{array}$ & $\begin{array}{l}\text { Follow- } \\
\text { up } \\
\text { [years] }\end{array}$ & $\begin{array}{l}\text { ICCI } \\
\text { ECC } \\
\text { in DM }\end{array}$ & $\begin{array}{l}\text { Adjusted RR } \\
\text { (95\% Cl) }\end{array}$ & Adjustments \\
\hline $\begin{array}{l}\text { Adami et al. } \\
\text { [33]/Sweden/1996 }\end{array}$ & 153852 & 74 male: $64 \%$ & $\begin{array}{l}\text { Hospital } \\
\text { discharge } \\
\text { diagnosis }\end{array}$ & $\begin{array}{l}\text { Cancer } \\
\text { registry }\end{array}$ & 6.7 & 272 & $\begin{array}{l}\text { ECC: } 1.4 \\
(1.1-1.8)\end{array}$ & $\begin{array}{c}\text { Alcohol use, } \\
\text { hepatitis, cirrhosis, } \\
\text { jaundice, etc }\end{array}$ \\
\hline $\begin{array}{l}\text { Khan et al. } \\
\text { [34]/Japan/2006 }\end{array}$ & 56881 & $40-70$ & NA & $\begin{array}{l}\text { Cancer } \\
\text { registry }\end{array}$ & $18-20$ & 40 & $\begin{array}{l}\text { ECC: } 0.30 \\
(0.04-2.22)\end{array}$ & $\begin{array}{c}\text { Age, sex, race, } \\
\text { geographic location, } \\
\text { medicare/medical } \\
\text { enrolment }\end{array}$ \\
\hline $\begin{array}{l}\text { El-Serag et al. } \\
\text { [35]/USA/2009 }\end{array}$ & 718687 & 52 male: $97 \%$ & Registry & $\begin{array}{l}\text { Cancer } \\
\text { registry }\end{array}$ & 2.3 & NA & $\begin{array}{c}\text { CC: } 1.60 \\
(0.67-3.83)^{\mathrm{a}} \\
\text { ICC: } 2.54 \\
(1.31-4.94) \\
\text { ECC: } 1.04 \\
(0.59-1.83)\end{array}$ & $\begin{array}{l}\text { Age, gender, } \\
\text { baseline visit date, } \\
\text { type of visit }\end{array}$ \\
\hline $\begin{array}{l}\text { Jamal et al. } \\
\text { [36]/USA/2009 }\end{array}$ & 836283 & 65 male: $98 \%$ & $\begin{array}{l}\text { Hospital } \\
\text { discharge } \\
\text { diagnosis }\end{array}$ & $\begin{array}{l}\text { Cancer } \\
\text { registry }\end{array}$ & NA & NA & $\begin{array}{l}\text { ECC: } 2.1 \\
(1.6-2.5)\end{array}$ & $\begin{array}{l}\text { Age, sex, race, } \\
\text { geographic region }\end{array}$ \\
\hline $\begin{array}{l}\text { Hemminki et al. } \\
\text { [37]/Sweden/2010 }\end{array}$ & 125126 & > 39 male: NA & $\begin{array}{l}\text { Medical } \\
\text { records }\end{array}$ & $\begin{array}{l}\text { Cancer } \\
\text { registry }\end{array}$ & 15 & 566 & $\begin{array}{l}\text { ECC: } 2.53 \\
(1.44-4.11)\end{array}$ & Age \\
\hline
\end{tabular}

AORs - adjusted odds ratios, Cl - confidence interval, DM - diabetes mellitus, CC - cholangiocarcinoma, ECC-extrahepatic cholangiocarcinoma, ICC intrahepatic cholangiocarcinoma, NA - not available, RR - relative risk, ${ }^{a} T$ The $A O R$ and $95 \%$ confidence intervals were derived by pooling the site-specific RRs

based on self-reported history or registry of disease $[34,36]$. The ascertainment of outcome was based on cancer registry in all studies. Potential confounders (at least for age) were controlled in all studies. The Newcastle-Ottawa scale was adopted in our quality assessment. The maximum score was 9, and all studies scored 7 or higher.

\section{Diabetes mellitus and risk of cholangiocarcinoma}

Six case-controlled studies and one cohort study reported results on DM and risk of CC (or risk of ICC and ECC, respectively) (Figure 1). Of these, four studies found statistically significant positive relationships $[21,25,31$, 32], and the other three studies did not find a signifi-

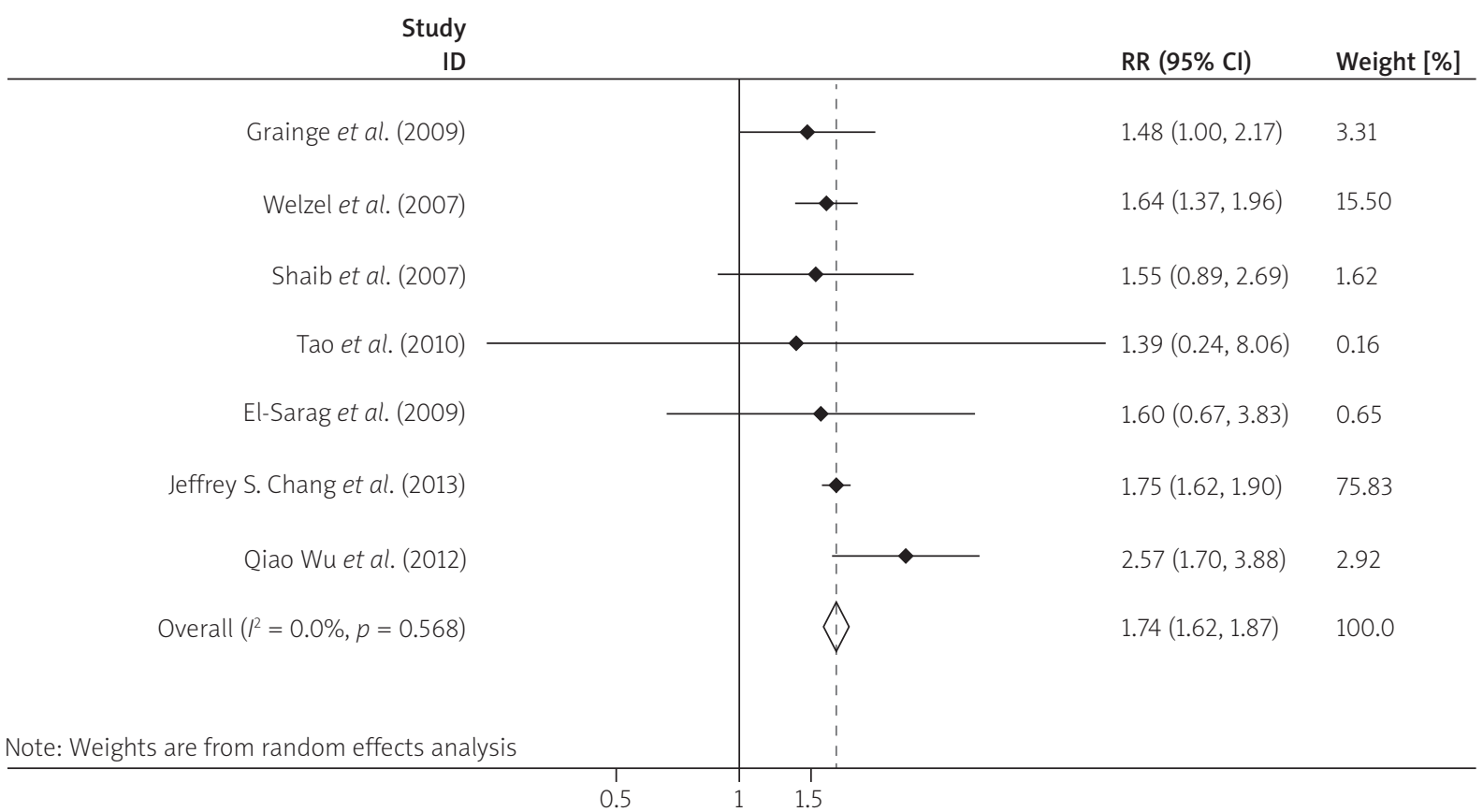

Figure 1. Forest plot of the relationships between diabetes and CC risk 


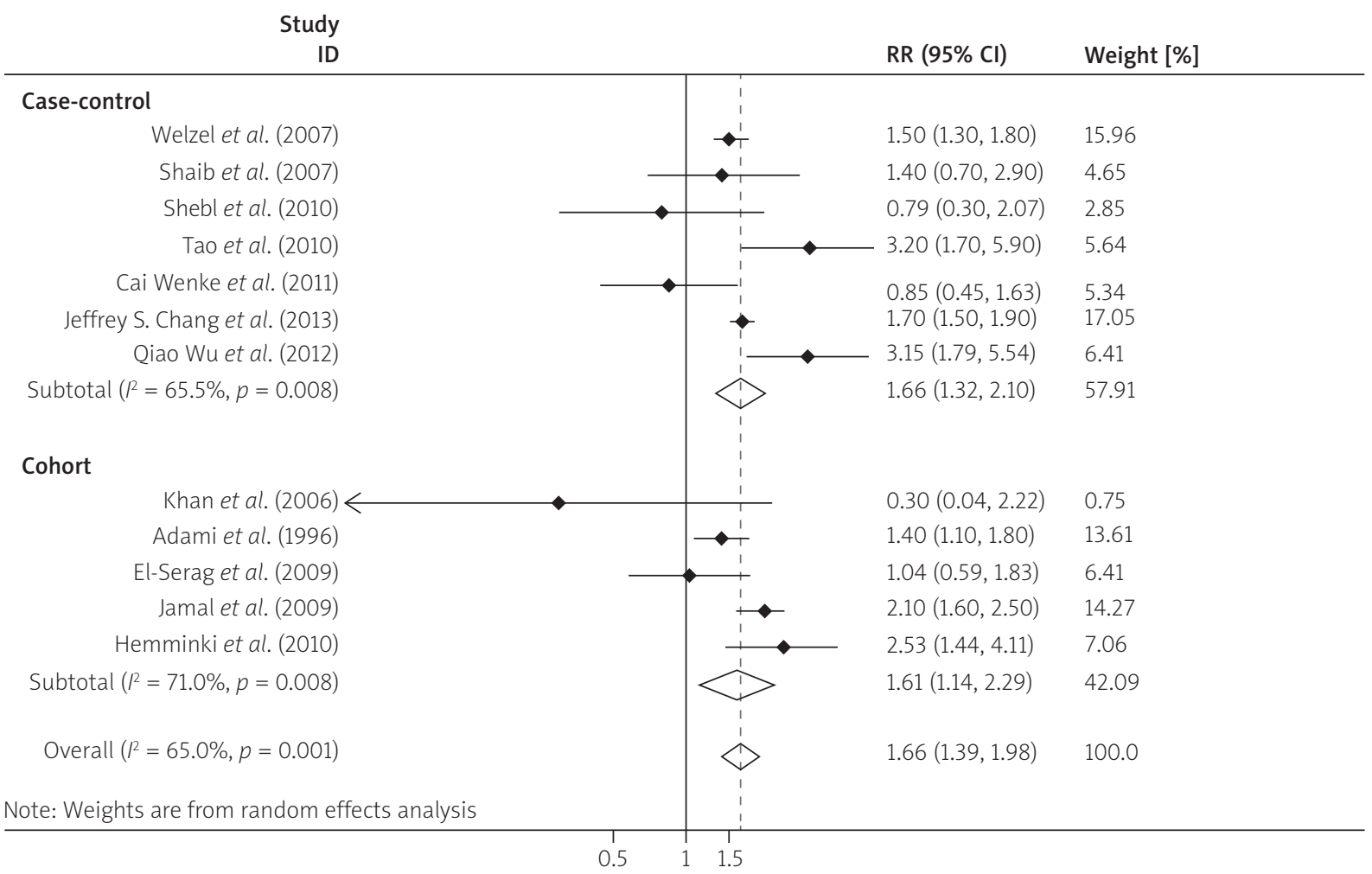

Figure 2. Forest plot of the relationship between DM and ECC risk in case-controlled studies and cohort studies

cantly increased risk of CC in patients with diabetes [22, $27,35]$. In the analysis of all five studies that reported RR of DM and CC, the summary RR and corresponding $95 \% \mathrm{Cl}$ were $1.74(95 \% \mathrm{Cl}: 1.62-1.87)$ in a random-effects model for those with diabetes compared with those without diabetes. There was no statistically significant heterogeneity among studies $\left(p=0.568 ; P^{2}=0 \%\right)$.

\section{Diabetes mellitus and risk}

\section{of extrahepatic cholangiocarcinoma}

We identified 12 studies (7 case-controlled and five cohort studies) that presented results on diabetes and risk of ECC (Figure 2). Of these, 7 studies found an increased risk of ECC in patients with diabetes [21, 27, 33, $36,37]$, and in another five studies positive relationships were not found [22, 26, 30, 34, 35]. In the analysis of all studies, the summary RR of ECC were 1.66 (95\% Cl: $1.39-1.98 ; p=0.001$ for heterogeneity) in a random-effects model for those with diabetes compared with those without diabetes, with evidence of significant heterogeneity among studies $(Q=31.42, p=0.001$, $\left.P^{2}=65 \%\right)$. We then conducted subgroup meta-analyses by geographic area and study design (Table III). The summary RR of the associations between diabetes and ECC risk were similar for cohort studies and case-con- trolled studies (summary RR (95\% Cl) 1.61 (1.14-2.29), in cohort studies and 1.66 (1.32-2.1) in case-controlled studies, respectively). We conducted subgroup analysis by geographic area (Figure 3). A significant association between DM and ECC risk was found in studies conducted in non-Asian regions (the USA and Europe) (summary RR, 1.62; 95\% Cl: 1.32-2.00) and in Asia (summary $R R, 1.60 ; 95 \%$ Cl: 1.01-2.54).

\section{Diabetes mellitus and intrahepatic cholangiocarcinoma risk}

We identified 11 case-controlled and one cohort study that presented results for the association of diabetes and ICC risk (Figure 4) [18-24, 27-29, 31, 32, 35]. Five of these 12 studies found a statistically significant positive association (range of individual RR, 0.53-3.2; summary RR for all 12 studies, 1.93; 95\% Cl: 1.65-2.25). There was significant heterogeneity among studies ( $p=0.037, l^{2}=46.9 \%$ ). Subgroup meta-analyses by study design indicated that the positive association was significant not only among case-controlled studies (summary RR, 1.90; 95\% Cl: 1.62-2.23; $p=0.030$ for heterogeneity) but also among cohort studies (summary $\mathrm{RR}, 2.54$; 95\% Cl: 1.31-4.93) (Table III). In addition, we also conducted subgroup analysis by geographic 
Table III. Summarised relative risks for the association between diabetes and ECC and ICC by study characteristics

\begin{tabular}{|c|c|c|c|c|c|c|}
\hline \multicolumn{2}{|c|}{ Subgroup } & \multirow[t]{2}{*}{ Number of studies } & \multirow[t]{2}{*}{ Relative risk $(95 \% \mathrm{Cl})$} & \multicolumn{3}{|c|}{ Tests for heterogeneity } \\
\hline & & & & $Q$ & $p$ & $P^{2}(\%)$ \\
\hline \multirow[t]{6}{*}{ ECC } & Geographical region: & & & & & \\
\hline & Asia & 6 & $1.60(1.01-2.54)$ & 18.19 & 0.003 & 72.5 \\
\hline & Non-Asian & 6 & $1.62(1.32-2.00)$ & 12.70 & 0.026 & 60.6 \\
\hline & Study design: & & & & & \\
\hline & Case-control study & 7 & $1.66(1.32-2.10)$ & 17.38 & 0.008 & 65.5 \\
\hline & Cohort studies & 5 & $1.61(1.14-2.29)$ & 13.78 & 0.008 & 71.0 \\
\hline \multirow[t]{6}{*}{ ICC } & Geographical region: & & & & & \\
\hline & Asia & 7 & $1.82(1.27-2.60)$ & 18.50 & 0.005 & 67.6 \\
\hline & Non-Asian & 5 & $1.88(1.66-2.12)$ & 2.19 & 0.701 & 0.0 \\
\hline & Study design: & & & & & \\
\hline & Case-control study & 11 & $1.90(1.62-2.23)$ & 19.91 & 0.030 & 49.8 \\
\hline & Cohort studies & 1 & $2.54(1.31-4.93)$ & - & - & - \\
\hline
\end{tabular}

Cl-confidence interval, ECC - extrahepatic cholangiocarcinoma, ICC - intrahepatic cholangiocarcinoma.

\section{Study \\ ID}

Asia
Khan et al. (2006)
Shebl et al. (2010)
Tao et al. (2010)
Cai Wenke et al. (2011)

Jeffrey S. Chang et al. (2013)

Qiao Wu et al. (2012)

Subtotal $\left(R^{2}=72.5 \%, p=0.003\right)$

\section{Non-Asia}

Welzel et al. (2007)

Shaib et al. (2007)

Adami et al. (1996)

El-Sarag et al. (2009)

Jamal et al. (2009)

Hemminki et al. (2010)

Subtotal $\left(R^{2}=60.6 \%, p=0.026\right)$

Overall $\left(P^{2}=65.0 \%, p=0.001\right)$

\section{RR $(95 \% \mathrm{Cl}) \quad$ Weight [\%]}

$0.30(0.04,2.22) \quad 0.75$

$0.79(0.30,2.07) \quad 2.85$

$3.20(1.70,5.90) \quad 5.64$

$0.85(0.45,1.63) \quad 5.34$

$1.70(1.50,1.90) \quad 17.05$

$3.15(1.79,5.54) \quad 6.41$

$1.60(1.01,2.54) \quad 38.04$

$1.50(1.30,1.80) \quad 15.96$

$1.40(0.70,2.90) \quad 4.65$

$1.40(1.10,1.80) \quad 13.61$

$1.04(0.59,1.83) \quad 6.41$

$2.10(1.60,2.50) \quad 14.27$

$2.53(1.44,4.11) \quad 7.06$

$1.62(1.32,2.00) \quad 61.96$

$1.66(1.39,1.98) \quad 100.0$

Note: Weights are from random effects analysis

Figure 3. Forest plot of the relationship between DM and ECC risk for twelve studies by geographic region

area (Figure 5). The association between diabetes and ICC risk was significantly positive in studies conducted in both Asian (summary RR, 1.82; 95\% Cl: 1.27-2.60; $p=0.005$ for heterogeneity) and in non-Asian regions (summary RR, 1.88; 95\% Cl: 1.66-2.12; $p=0.701$ for heterogeneity).

\section{Publication bias}

The funnel plot revealed no evidence for publication bias concerning diabetes and the risk of CC, either in Egger's and Begg's tests or visualisation of the Begg's funnel plot (Egger's test: ECC, $p=0.661$, ICC, $p=0.735$; Begg's tests: ECC, $p=0.15$, ICC, $p=0.373$ ). 


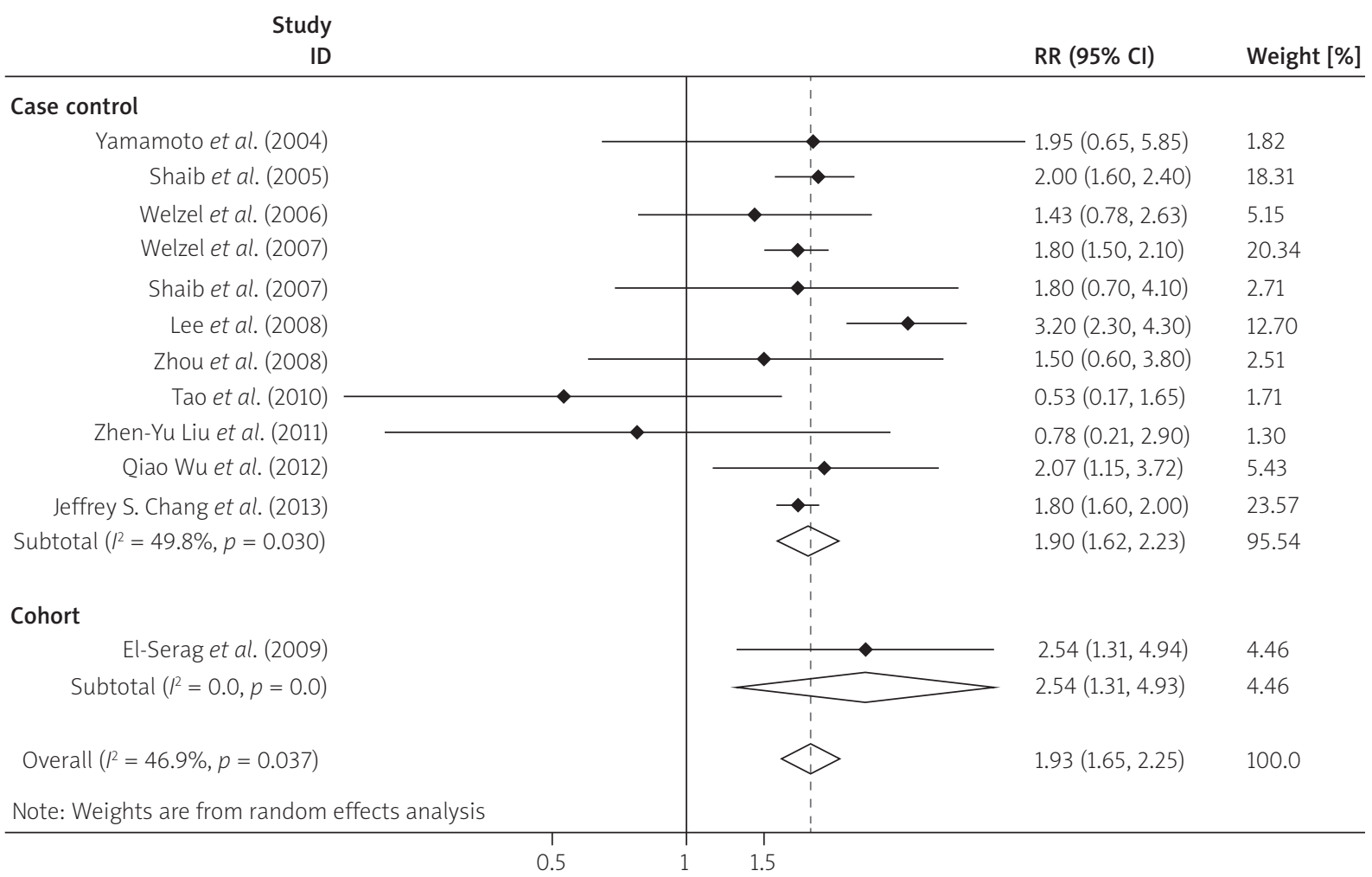

Figure 4. Forest plot of the relationship between DM and ICC risk in case-controlled studies and cohort studies

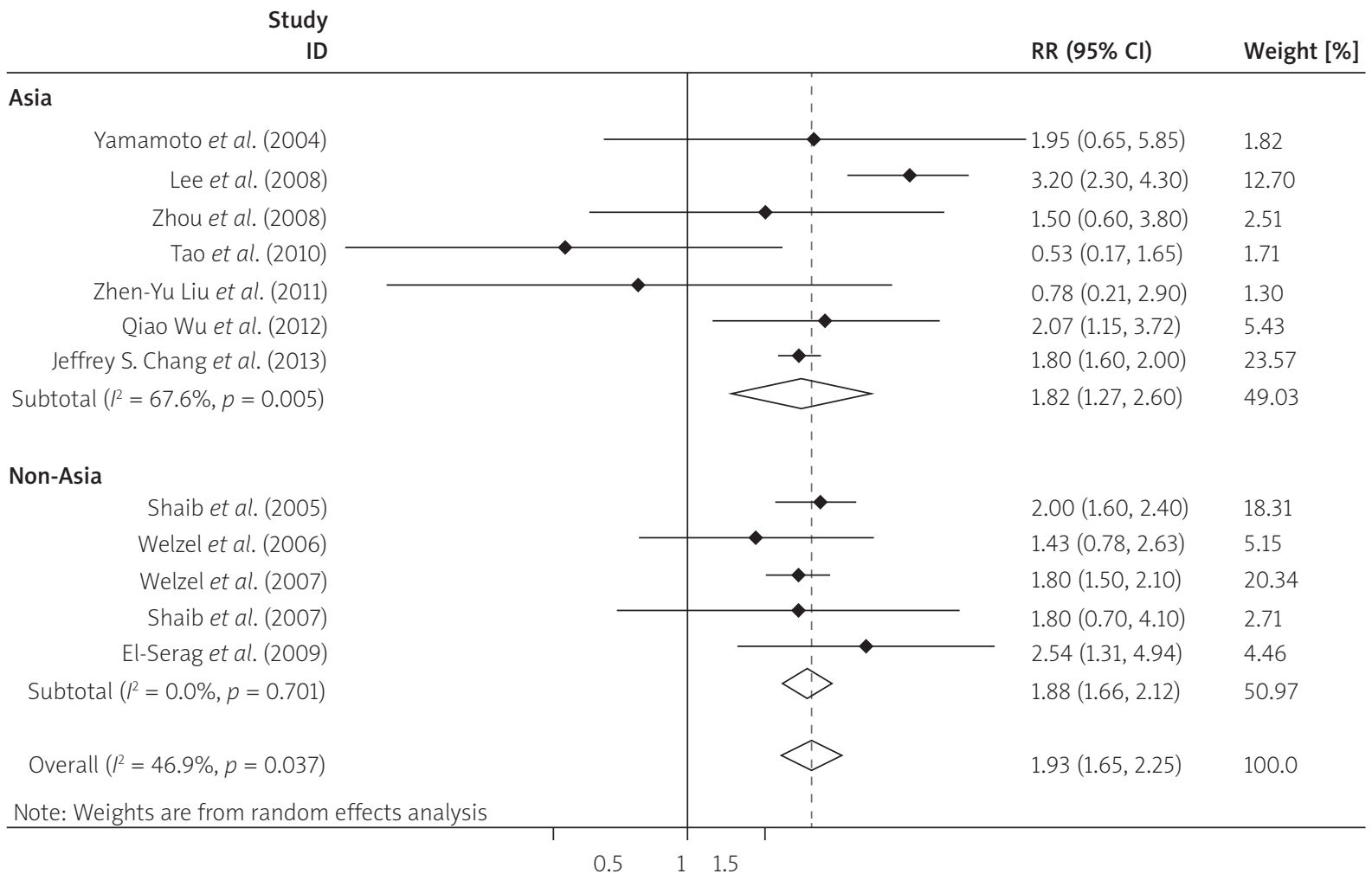

Figure 5. Forest plot of the relationship between DM and ICC risk for twelve studies by geographic region 
A sensitivity analysis, which was performed to evaluate the stability, revealed that there was no significant impact on the overall results with removal of any of the studies.

\section{Discussion}

In this meta-analysis, we reviewed the case-control studies and cohort studies with information of diabetes and CC in two regions. The overall result suggests a positive association between diabetes and the risk of CC. Even though among diabetic individuals absolute risks of CC are low, our results have important clinical and public health significance. Diabetes may be a pathogenic factor for the development of CC. Sub-group analysis showed that this increased risk was largely attributed to the summary risk estimates from case-controlled studies and cohort studies. Although some meta-analyses were conducted with respect to the relationship between diabetes and CC, some other meta-analyses were conducted with respect to the relationship between diabetes and ICC or extrahepatic cholangiocarcinoma ECC. We screened more studies in this meta-analysis to quantitatively assess the relation between diabetes and CC, including CC, ICC, ECC and a significant association between $D M$ and ECC risk was found in non-Asian regions and Asian regions. This result is different from other previous meta-analysis.

Diabetes is a common disease all over the world, and its incidence and mortality is increasing. In many countries diabetes and its comorbidities have become a major public health concern. Epidemiological studies have provided strong evidence that diabetes can increase the incidence of many types of cancer (including cancers of the breast, endometrium, non-Hodgkin's lymphoma, pancreas, and the liver) [38, 39]. Many studies found that pancreatic gland disease (pancreatic cancer, pancreatitis) is associated with DM. The results from the present meta-analysis suggest that diabetes may be a pathogenic factor for the development of cancer. Insulin-like growth factor-1 and insulin play an important role in the course of malignant transformation in the tissues of the colon, breast, lung, bladder, and prostate. Studies have confirmed that insulin can stimulate growth of many malignant tumour cell lines, and thus up-regulate the level of IGFs [40]. Some studies have suggested that diabetes increases the incidence of CC and level of IGF-1 associated with the development and progression of CC [19, 21, 25, 41]. In some studies, DM has been considered to be an independent risk factor for cholelithiasis [42, 43], which is one of the primary risk factors for CC. Inflammatory cytokines produced by adipose tissues, such as interleukin-6, monocyte chemoattractant protein, and plasminogen activator inhibitor-1, may play important roles in carcinogenesis, cancer progression, and poor prognosis. These may be the possible mechanisms whereby diabetes causes CC.

Heterogeneity across studies is often a concern in a meta-analysis. It was not surprising that a certain degree of heterogeneity was observed given the between-study variation, such as race, study design, and sample source. The degree of heterogeneity was somewhat attenuated among the studies conducted in Asian countries, suggesting that race may be a potential source of heterogeneity. However, meta-regression was adopted and no variables were identified as potential contributors to heterogeneity.

Some potential limitations should be considered in the present meta-analysis. First, since we only searched papers in English and Chinese, the completeness of evidence is impeded by language bias. Second, most of the studies did not distinguish between type 1 and type 2 diabetes, which might attenuate any true relationship between diabetes and CC risk. Third, confusion is also likely to be present because these two diseases share several risk factors, such as aging, smoking, alcohol consumption, and obesity. However, the relationship between these two diseases' risk factors was only marginally attenuated after adjustment for a wide range of potential confounders. Finally, as in any meta-analysis, the possibility of publication bias is of concern, because small studies with null results tend not to be published. Publication bias may have resulted in an overestimate of the relationship between DM and risk of CC. However, the results obtained from funnel plot analysis and formal statistical tests did not provide evidence for such a bias. Last but not least is the number of included studies. More studies, especially cohort studies, about the association of diabetes and CC risk are needed to update the results.

\section{Conclusions}

The current meta-analysis showed that diabetes may increase the risk of CC. Well-designed cohort studies are warranted to confirm this association.

\section{Conflict of interest}

The authors declare no conflict of interest.

\section{References}

1. Patel T. Cholangiocarcinoma. Nat Clin Pract Gastroenterol Hepatol 2006; 3: 33-42.

2. Taylor-Robinson SD, Toledano MB, Arora S, et al. Increase in mortality rates from intrahepatic cholangiocarcinoma in England and Wales 1968-1998. Gut 2001; 48: 816-20. 
3. Khan SA, Emadossadaty S, Ladep NG, et al. Rising trends in cholangiocarcinoma: is the ICD classification system misleading us? J Hepatol 2012; 56: 848-54.

4. Seyama Y, Makuuchi M. Current surgical treatment for bile duct cancer. World J Gastroenterol 2007; 13: 1505-15.

5. Claessen MM, Vleggaar FP, Tytgat KM, et al. High lifetime risk of cancer in primary sclerosing cholangitis. J Hepatol 2009; 50: 158-64.

6. Tyson GL, El-Serag HB. Risk factors for cholangiocarcinoma Hepatology 2011; 54: 173-84.

7. Khan SA, Toledano MB, Taylor-Robinson SD. Epidemiology, risk factors, and pathogenesis of cholangiocarcinoma. HPB (Oxford) 2008; 10: 77-82.

8. Adenugba A, Khan SA, Taylor-Robinson SD, et al. Polychlorinated biphenyls in bile of patients with biliary tract cancer. Chemosphere 2009; 76: 841-6.

9. Noel MS, Hezel AF. New and emerging treatment options for biliary tract cancer. Onco Targets Ther 2013; 6: 1545-52.

10. Malek M, Aghili R, Emami Z, Khamseh ME. Risk of cancer in diabetes: the effect of metformin. ISRN Endocrinol 2013; 2013: 636927.

11. El-Serag HB, Hampel H, Javadi F. The association between diabetes and hepatocellular carcinoma: a systematic review of epidemiologic evidence. Clin Gastroenterol Hepatol 2006; 4 369-80.

12. Ben Q, Cai Q, Li Z, et al. The relationship between new-onset diabetes mellitus and pancreatic cancer risk: a case-control study. Eur J Cancer 2011; 47: 248-54.

13. Stroup DF, Berlin JA, Morton SC, et al. Meta-analysis of observational studies in epidemiology: a proposal for reporting. Meta-analysis Of Observational Studies in Epidemiology (MOOSE) group. JAMA 2000; 283: 2008-12.

14. Higgins JP, Thompson SG, Deeks J, Altman DG. Measuring inconsistency in meta-analyses. BMJ 2003; 327: 557-60.

15. Mantel N, Haenszel W. Statistical aspects of the analysis of data from retrospective studies of disease. J Natl Cancer Inst 1959; 22: 719-48.

16. DerSimonian R, Laird N. Meta-analysis in clinical trials. Control Clin Trials 1986; 7: 177-88.

17. Egger M, Davey Smith G, Schneider M, Minder C. Bias in meta-analysis detected by a simple, graphical test. BMJ 1997; 315: 629-34.

18. Yamamoto S, Kubo S, Hai S, et al. Hepatitis C virus infection as a likely etiology of intrahepatic cholangiocarcinoma. Cancer Sci 2004; 95: 592-5

19. Shaib YH, El-Serag HB, Davila JA, et al. Risk factors of intrahepatic cholangiocarcinoma in the United States: a case-control study. Gastroenterology 2005; 128: 620-6.

20. Welzel TM, Mellemkjaer L, Gloria G, et al. Risk factors for intrahepatic cholangiocarcinoma in a low-risk population: a nationwide case-control study. Int J Cancer 2007; 120: 638-41.

21. Welzel TM, Graubard BI, El-Serag HB, et al. Risk factors for intrahepatic and extrahepatic cholangiocarcinoma in the United States: a population-based case-control study. Clin Gastroenterol Hepatol 2007; 5: 1221-8.

22. Shaib YH, El-Serag HB, Nooka AK, et al. Risk factors for intrahepatic and extrahepatic cholangiocarcinoma: a hospital-based case-control study. Am J Gastroenterol 2007; 102: 1016-21.
23. Lee TY, Lee SS, Jung SW, et al. Hepatitis B virus infection and intrahepatic cholangiocarcinoma in Korea: a case-control study. Am J Gastroenterol 2008; 103: 1716-20.

24. Zhou YM, Yin ZF, Yang JM, et al. Risk factors for intrahepatic cholangiocarcinoma: a case-control study in China. World J Gastroenterol 2008; 14: 632-5.

25. Grainge MJ, West J, Solaymani-Dodaran M, et al. The antecedents of biliary cancer: a primary care case-control study in the United Kingdom. Br J Cancer 2009; 100: 178-80.

26. Shebl FM, Andreotti G, Rashid A, et al. Diabetes in relation to biliary tract cancer and stones: a population-based study in Shanghai, China. Br J Cancer 2010; 103: 115-9.

27. Tao LY, He XD, Qu Q, et al. Risk factors for intrahepatic and extrahepatic cholangiocarcinoma: a case-control study in China. Liver Int 2010; 30: 215-21.

28. Cai WK, Sima H, Chen BD, Yang GS. Risk factors for hilar cholangiocarcinoma: a case-control study in China. World J Gastroenterol 2011; 17: 249-53.

29. Liu ZY, Zhou YM, Shi LH, Yin ZF. Risk factors of intrahepatic cholangiocarcinoma in patients with hepatolithiasis: a case-control study. Hepatobiliary Pancreat Dis Int 2011; 10: 626-31.

30. Peng NF, Li LQ, Qin X, et al. Evaluation of risk factors and clinicopathologic features for intrahepatic cholangiocarcinoma in Southern China: a possible role of hepatitis B virus. Ann Surg Oncol 2011; 18: 1258-66.

31. Wu Q, He XD, Yu L, et al. The metabolic syndrome and risk factors for biliary tract cancer: a case-control study in China. Asian Pac J Cancer Prev 2012; 13: 1963-9.

32. Chang JS, Tsai CR, Chen LT. Medical risk factors associated with cholangiocarcinoma in taiwan: a population-based case-control study. PLoS One 2013; 8: e69981.

33. Adami HO, Chow WH, Nyren O, et al. Excess risk of primary liver cancer in patients with diabetes mellitus. J Natl Cancer Inst 1996; 88: 1472-7.

34. Khan M, Mori M, Fujino Y, et al. Site-specific cancer risk due to diabetes mellitus history: evidence from the Japan Collaborative Cohort (JACC) Study. Asian PaC J Cancer Prev 2006; 7: 253-9.

35. El-Serag HB, Engels EA, Landgren O, et al. Risk of hepatobiliary and pancreatic cancers after hepatitis $C$ virus infection: a population-based study of U.S. veterans. Hepatology 2009; 49: 116-23.

36. Jamal MM, Yoon EJ, Vega KJ, et al. Diabetes mellitus as a risk factor for gastrointestinal cancer among American veterans. World J Gastroenterol 2009; 15: 5274-8.

37. Hemminki K, Li X, Sundquist J, Sundquist K. Risk of cancer following hospitalization for type 2 diabetes. Oncologist 2010; 15: 548-55

38. Rousseau MC, Parent ME, Pollak MN, Siemiatycki J. Diabetes mellitus and cancer risk in a population-based case-control study among men from Montreal, Canada. Int J Cancer 2006; 118: 2105-9.

39. Huxley R, Ansary-Moghaddam A, Berrington de Gonzalez A, et al. Type-Il diabetes and pancreatic cancer: a meta-analysis of 36 studies. Br J Cancer 2005; 92: 2076-83.

40. Gallagher EJ, LeRoith D. Minireview: IGF, insulin, and cancer. Endocrinology 2011; 152: 2546-51. 
41. Fedirko V, Lukanova A, Bamia C, et al. Glycemic index, glycemic load, dietary carbohydrate, and dietary fiber intake and risk of liver and biliary tract cancers in Western Europeans. Ann Oncol 2013; 24: 543-53.

42. Biddinger SB, Haas JT, Yu BB, et al. Hepatic insulin resistance directly promotes formation of cholesterol gallstones. Nat Med 2008; 14: 778-82.

43. Festi D, Dormi A, Capodicasa S, et al. Incidence of gallstone disease in Italy: results from a multicenter, population-based Italian study (the MICOL project). World J Gastroenterol 2008; 14: 5282-9.

Received: 23.09 .2014

Accepted: 24.10 .2014 